Jurnal Pemikiran \& Penelitian Psikologi

\title{
PSIKOLOGIA
}

p-ISSN: $185-0327$

e-ISSN: $2549-2136$

www.jurnal.usu.ac.id/psikologia

\section{PENGARUH RELIGIUSITAS TERHADAP PSYCHOLOGICAL WELL BEING (PWB) PADA PENSIUNAN SUKU BATAK TOBA}

\section{THE INFLUENCE OF RELIGIOSITY TO THE PSYCHOLOGICAL WELL BEING (PWB) OF BATAK TOBA ETHNIC RETIRED}

Sarah Yunianty Situmorang, Elvi Andriani

Psikologia: Jurnal Pemikiran \& Penelitian Psikologi

Tahun 2018, Vol. 13, No. 2, hal.74-86

Artikel ini dapat diakses dan diunduh pada:

www.jurnal.usu.ac.id/psikologia

Dipublikasikan oleh:

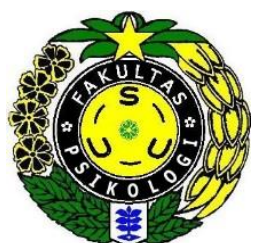

Fakultas Psikologi

Universitas Sumatera Utara

Jl. Dr. Mansyur No. 7 Medan. Telp/fax: 061-8220122

Email: psikologia@usu.ac.id 


\title{
PENGARUH RELIGIUSITAS TERHADAP PSYCHOLOGICAL WELL BEING (PWB) PADA PENSIUNAN SUKU BATAK TOBA
}

\author{
Sarah Yunianty Situmorang \& Elvi Andriani
}

Universitas Sumatera Utara

\begin{abstract}
ABSTRAK
Penelitian ini bertujuan untuk mengetahui pengaruh religiusitas terhadap Psychological Well Being pada pensiunan Suku Batak Toba. Psychological Well Being merupakan istilah yang digunakan untuk menggambarkan kesehatan fungsi psikologis individu berdasarkan sejauh mana individu memiliki tujuan hidup, menyadari potensi-potensi yang dimiliki, kualitas hubungannya dengan orang lain, sejauh mana bertanggung jawab atas kehidupannya sendiri, serta berusaha mengembangkan dan mengeksplorasi dirinya. Religiusitas didefinisikan sebagai pemahaman akan ilmu dan keyakinan, perasaan atau hubungan emosional, serta perilaku dalam beragama. Pensiunan Suku Batak Toba, yang menjadi sampel penelitian ini, merupakan para lansia Batak Toba beragama Kristen yang telah pensiun dari pekerjaannya. Metode penelitian ini adalah metode kuantitatif, dengan teknik analisis data yang digunakan adalah analisis regresi sederhana. Hasil utama dari penelitian menunjukkan bahwa religiusitas berpengaruh terhadap Psychological Well Being, dengan sumbangan sebesar 21.3\% $\left(\mathrm{R}^{2}=0.213\right)$, dimana $78.7 \%$ dijelaskan oleh faktor-faktor lainnya.
\end{abstract}

Kata kunci : Psychological Well Being, Religiusitas, Pensiunan Suku Batak Toba

\section{THE INFLUENCE OF RELIGIOSITY TO THE PSYCHOLOGICAL WELL BEING (PWB) OF BATAK TOBA ETHNIC RETIRED}

\begin{abstract}
This study aimed to determine the influence of religiosity to the Psychological Well Being of Batak Toba Ethnic retired. Psychological Well Being is a term used to describe individual's psychological functioning based on the extent to which an individual have a purpose in life, realize the potential, quality of relationship with others, the extent of responsibility of their own life, and strive to develop and explore themselves. Religiosity is defined as the understanding of konwledge and belief, feeling or emotional relation, as well as in religious behavior. Batak Toba Ethnic retired, as samples of this study, were Christian retired from Batak Toba Ethnic who had retired from job. The research method of this study is a quantitative method, with simple regression as its analysis technique. The main result shows that religiosity influence Psychological Well Being with $21.3 \%$ of contribution $\left(\mathrm{R}^{2}=.0213\right)$, which $78.7 \%$ are explained by other factors.
\end{abstract}

Keywords : Psychological Well Being, Religiosity, Batak Toba Ethnic Retired

*Korespondensi mengenai penelitian ini dapat dilayangkan kepada: psikologia@usu..ac.id
Rekomendasi mensitasi:

Situmorang, S. Y., Andriani, E. (2018).Pengaruh Religiusitas terhadap Psychological Well Being (PWB) pada Pensiunan Suku Batak Toba. Psikologia :Jurnal Pemikiran dan Penelitian Psikologi, 13(2), -86 
Sebagai manusia, menjadi tua adalah suatu hal yang pasti terjadi dan tidak dapat dihindari. Masa tua ditandai dengan usia lanjut yang merupakan periode terakhir dalam hidup manusia. Lansia dibagi menjadi dua bagian yaitu lansia dini berusia antara $60-70$ tahun dan lansia berusia 70 tahun sampai akhir kehidupan (Hurlock, 2002). Menurut Badan Pusat Statistik Kota Medan berdasarkan Sensus Penduduk 2010 jumlah penduduk lansia di kota Medan mencapai 117.216 orang $(5.59 \%)$ yang meningkat jumlahnya dari tahun 2005 sebesar 77.837 orang (3.85\%). Masa lansia dialami dengan cara yang berbeda-beda, ada lansia yang mampu melihat arti penting masa lansia tersebut sebagai masa hidup yang memberi mereka kesempatan untuk berkembang dan berbahagia, namun ada juga lansia yang memandang masa tua dengan sikap pasrah, keputusasaan dan penolakan, yang akan mempercepat proses kemerosotan mental dan jasmani mereka sendiri (Calhoun, 1995). Masa lansia sering diidentikkan dengan masa pensiun (Papalia, 2008).

Pensiun adalah sebuah konsep sosial yang memiliki beragam pengertian (Newman, 2006). Pensiun tidak hanya sekedar berhenti bekerja karena usia. Sebagai sebuah istilah, pensiun kurang lebih bermakna purnabakti, tugas selesai, atau berhenti (Sutarto, 2008). Parnes dan Nessel (dalam Corsini, 1987) mengatakan bahwa pensiun adalah suatu kondisi dimana seorang individu berhenti bekerja dari suatu pekerjaan yang biasa dilakukan. Pensiun dapat menyangkut perubahan peran, perubahan keinginan dan nilai, dan perubahan secara keseluruhan terhadap pola hidup (Schwartz dalam Hurlock, 2002). Berdasarkan pandangan psikologi perkembangan, pensiun dapat dijelaskan sebagai masa transisi ke pola hidup baru, maupun merupakan akhir pola hidupnya, apalagi karena usianya sudah lanjut dan harus diperhentikan (Agustina, 2008).

Masa pensiun dapat memberikan efek positif dan efek negatif bagi lansia. Efek positif pada masa pensiun muncul karena lansia melakukan penyesuaian diri yang baik, sehingga lansia mengalami tahap ego integrity. Ego integrity diartikan sebagai pengetahuan tentang makna hidup, keseimbangan antara kebutuhan pribadi dengan orang lain, memberikan yang terbaik dalam perilaku dan mencapai prestasi (Santrock, 1998). Efek negatif masa pensiun muncul karena penyesuaian diri yang buruk, sehingga lansia mengalami despair. Despair diartikan sebagai kondisi dimana tidak adanya harapan dan sebuah perasaan bahwa segala sesuatu adalah salah serta tidak akan berakhir dengan baik. Despair pada masa pensiun dapat menambah kecemasan pada lansia (Santrock, 1998). Tanpa adanya stimulus kondisi pensiun, kebanyakan lansia telah mengalami kecemasan akan tugas perkembangannya. Perasaan seperti loneliness dan isolasi sosial akan muncul, dimana hal tersebut merupakan efek utama dalam menghadapi pensiun. Perasaan-perasaan seperti ini cukup kritis dalam perjalanan hidup pensiunan dan kelak akan mempengaruhi Psychological Well Being-nya (Papalia, 2001).

Psychological Well Being (PWB) merupakan istilah yang digunakan untuk menggambarkan kesehatan psikologis individu berdasarkan pemenuhan kriteria fungsi psikologi positif (Ryff, 1995). Ryff dan Keyes (1995) memberikan gambaran yang lebih komprehensif mengenai Psychological Well Being (PWB) dalam pendapatnya yang tercantum pada kutipan berikut:

"Comprehensive accounts of psychological well being need (to) probe people's sense of whether their lives has purpose, whether they're realizing their given potential, what is the quality of their ties to others, and if they feel in charge of their own lives." (Ryff \& Keyes, 1995).

Berdasarkan kutipan di depan, dapat disimpulkan bahwa Psychological Well Being (PWB) memandang sejauh mana seorang individu memiliki tujuan dalam hidupnya, apakah mereka menyadari potensi-potensi yang dimiliki, kualitas hubungannya dengan orang lain, dan sejauh mana mereka merasa bertanggung jawab atas kehidupannya sendiri.

Psychological Well Being (PWB) adalah suatu kondisi psikologis individu yang ditandai dengan berfungsinya aspek-aspek psikologis positif. Ryff (1989) mengkonstruksikan aspekaspek Psychological Well Being (PWB), antara lain: penerimaan diri, hubungan positif dengan orang lain, kemandirian, penguasaan lingkungan, tujuan hidup dan pengembangan pribadi. 
Terdapat beberapa faktor yang mempengaruhi Psychological Well Being (PWB), salah satu diantaranya adalah religiusitas. Religiusitas biasanya didefinisikan sebagai pemahaman ilmu agama, efek yang harus dilakukan dengan hubungan atau perasaan emosional, dan/atau perilaku, seperti kehadiran di tempat ibadah, membaca kitab suci, dan ibadah (Cornwall et al., 1986). Menurut Kwon (2003), religiusitas didefinisikan sebagai sejauh mana seseorang percaya dan memandang hal-hal yang terjadi sehari-hari berdasarkan sudut pandang agama, serta menerapkan keyakinan agamanya pada kehidupan sehari-hari.

Salah satu faktor yang mempengaruhi religiusitas adalah faktor alami, yang berkaitan dengan berbagai jenis pengalaman emosional dalam beragama (Thouless, 2000). Seperti yang diutarakan Ibu R, jemaat HKBP (Huria Kristen Batak Protestan) $\mathrm{X}$ di Medan, sambil menunggu anggota yang lain untuk berlatih paduan suara, dalam kutipan berikut (komunikasi personal, 3 November 2013) :

"kami-kami ini kan udah tua, udah enggak kerja lagi. Jarang keluar rumah juga. Jadi yaa.. lewat kegiatan-kegiatan di gereja inilah bisa ngumpul ramai-ramai sama teman-teman yang lain, ketawaketawa, cerita-cerita sambil menyalurkan talenta suara yang Tuhan kasi sama kita. Orang Batak kan gitu, kalo udah jumpa pasti tak ada habisnya yang dibicarakan. Tentu cerita soal kedekatan kita sama Tuhan dan menghadapi masamasa tua ini."

Lansia juga dapat berpartisipasi dalam beberapa praktik atau pelaksanaan sejumlah kegiatan dalam masa pensiun sebagai bentuk dari salah satu dimensi religiusitas, yaitu dimensi peribadatan (Glock dan Stark, 1962). Beberapa praktik atau kegiatan tersebut, antara lain: kelompok PA (Penelaahan Alkitab), persekutuan doa lansia, persekutuan para janda, partangiangan (dalam bahasa Batak Toba yang berarti kebaktian) yang dilaksanakan oleh gereja setiap minggu dan kumpulan marga yang biasanya dilaksanakan setiap bulan, STM
(Serikat Tolong Menolong) di lingkungan rumah, kelompok paduan suara, dsb.

Suku Batak merupakan salah satu dari ratusan suku yang ada di Indonesia. Suku Batak memiliki 6 (enam) suku bangsa, antara lain: Batak Toba, Batak Karo, Batak Simalungun, Batak Pakpak/Dairi, Batak Mandailing, dan Batak Angkola (Bangun dalam Koentjaraningrat, 2002). Diantara masyarakat Suku Batak, masyarakat dengan latar belakang suku Batak Toba memiliki jumlah terbesar atau mayoritas di kota Medan. Terdapat beberapa ciri khas masyarakat Batak Toba, seperti berbicara dengan nada tinggi, sangat ekspresif sehingga terkadang terkesan emosional, memahami silsilah marga (tarombo) untuk mengetahui letak kekerabatan dengan marga lain, dan dalam pekerjaan biasanya memperlihatkan sikap arogan.

Lansia juga dapat mengambil bagian dari salah satu tugas gereja Batak Toba yang menjadi dasar pelayanan di dalamnya, yaitu Marturia, Diakonia, dan Koinonia. Marturia (dalam bahasa Yunani : martyria) adalah istilah yang dipakai dalam melakukan aktivitas kesaksian iman, pengabaran maupun praktek penyampaian informasi mengenai ajaran Kristen kepada orang lain. Marturia tidak hanya bermakna bersaksi secara benar dan tepat tentang hal - hal yang pernah dilihat dan didengar, tetapi juga memperbincangkan kembali pengalaman pengalaman dan peristiwa yang dialami sebelumnya, serta tidak terbatas dalam gedung gereja. Diakonia (dalam bahasa Latin : diaconus) adalah suatu peranan dalam gereja yang umumnya diasosiasikan dengan pelayanan dalam berbagai bidang yang berbeda-beda. Pada masa kini, Diakonia memberi bantuan seperti pengobatan, panti asuhan, pendidikan, maupun penyediaan lapangan pekerjaan bagi mereka yang berkekurangan. Diakonia harus membawa perubahan kepada masyarakat dan dapat menjadi salah satu bentuk kepedulian gereja kepada masyarakat luas. Koinonia (anglikisasi

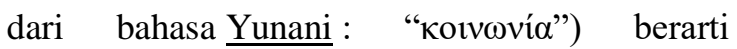
kelompok dengan partisipasi intim dan mempererat persaudaraan dimana semua orang menjadi satu di dalam Tuhan.

Dengan demikian, berdasarkan uraian yang telah dijelaskan di depan, peneliti tertarik untuk mengetahui pengaruh religiusitas terhadap 
Psychological Well Being (PWB) pada pensiunan Suku Batak Toba.

\section{Psychological Well Being (PWB)}

Psychological Well Being (PWB) merupakan integrasi dari teori-teori perkembangan manusia, teori psikologi klinis dan konsep mengenai kesehatan mental (Ryff, 1989). Psychological Well Being (PWB) sebagai suatu kondisi dimana seorang individu memiliki tujuan dalam hidupnya agar lebih bermakna, menyadari potensi-potensi yang dimiliki, menciptakan dan mengatur kualitas hubungannya dengan orang lain, sejauh mana mereka merasa bertanggung jawab atas kehidupannya sendiri, serta berusaha mengembangkan dan mengeksplorasi dirinya.

Menurut Ryff (1989) gambaran tentang karakteristik orang yang memiliki kesejahteraan psikologis merujuk pada pandangan Rogers tentang orang yang berfungsi penuh (fullyfunctioning person), pandangan Maslow tentang aktualisasi diri (self actualization), pandangan Jung tentang individuasi (individuation), konsep Allport tentang kematangan (maturity), juga sesuai dengan konsep Erikson dalam menggambarkan individu yang mencapai integration vs despair.

\section{Religiusitas}

Religiusitas biasanya didefinisikan keyakinan), efek yang harus dilakukan dengan hubungan emosional atau perasaan emosional, dan / atau perilaku, seperti kehadiran di tempat ibadah, membaca kitab suci, dan ibadah (Cornwall et al., 1986). Individu yang memiliki tingkat religiusitas tinggi lebih mampu memaknai kejadian hidupnya secara positif sehingga hidupnya menjadi lebih bermakna (Bastaman, 2000). Glock dan Stark (1962) merumuskan religiusitas sebagai komitmen religius yang berhubungan dengan agama atau keyakinan iman, yang dapat dilihat melalui aktivitas atau perilaku individu sesuai dengan agama atau keyakinan iman yang dianut.

Berdasarkan uraian diatas, maka religiusitas dapat didefinisikan sebagai pemahaman tentang ilmu agama atau keyakinandan komitmen religius, yang dapat dilihat melalui aktivitas atau perilaku individu sesuai dengan keyakinan yang dianut.

\section{Pensiun}

Pensiun adalah sebuah konsep sosial yang memiliki beragam pengertian (Newman, 2006). Pensiun tidak hanya sekedar berhenti bekerja karena usia. Pensiun merupakan masa putusnya hubungan kerja antara karyawan dengan tempat kerjanya. Pensiun merupakan hak dan kewajiban, merupakan hak karena seseorang berhak mengajukan pensiun kapan saja dan secara sukarela. Pensiun merupakan kewajiban karena seseorang harus segera pensiun jika sudah masanya, tanpa mempertimbangkan apakah masih senang bekerja atau tidak (Hurlock, 2002).

Pensiun merupakan suatu pemutusan hubungan kerja, bilamana karyawan mencapai saat dia berumur maksimum dan masa kerja maksimum menurut batas-batas yang ditentukan perusahaan/instansi (Tulus, 1996). Parnes dan Nessel (dalam Corsini, 1987) mengatakan bahwa pensiun adalah suatu kondisi dimana seorang individu berhenti bekerja dari suatu pekerjaan yang biasa dilakukan. Francis (2001) mengemukakan bahwa pensiun dapat diartikan sebagai masa tenang karena lepasnya aktivitas yang rutin dan masa menikmati masa tua dengan keluarga, namun ada juga lansia yang memandang pensiun sebagai masa kritis, dikarenakan persepsi orang lain terhadap dirinya yang sudah tidak berguna dan tidak kompeten lagi.

Berdasarkan uraian diatas, pensiun dapat didefinisikan sebagai suatu kondisi dimana seorang individu berhenti bekerja dari suatu pekerjaan yang biasa dilakukan, yang dipengaruhi oleh keadaan psikologis melalui aktivitas lain yang dilakukan.

\section{Lanjut Usia}

Lansia adalah masa dewasa akhir dimulai dari usia 60 tahun sampai akhir kehidupan, serta memiliki rentang kehidupan yang paling panjang dalam periode kehidupan manusia (Santrock, 2008). Berdasarkan UU No. 13/Th.1998 tentang kesejahteraan lanjut 
usiapada BAB I Pasal 1 Ayat 2, lanjut usia di Indonesia merupakan individu yang mencapai usia 60 (enam puluh) tahun ke atas. Lanjut usia dibagi menjadi usia lanjut dini yang berkisar antara usia 60 (enam puluh) sampai 70 (tujuh puluh) tahun dan usia lanjut yang dimulai pada usia tujuh puluh tahun hingga akhir kehidupan seseorang (Hurlock, 2002). Lanjut usia muda berkisar antara 65 (enam puluh lima) hingga 74 (tujuh puluh empat) tahun dan lanjut usia akhir berkisar antara 75 (tujuh puluh lima) tahun atau lebih (Baltes dalam Papalia, 2008).

Berdasarkan uraian diatas, maka lanjut usia dapat didefinisikan sebagai individu yang mencapai usia 60 (enam puluh) tahun ke atas hingga akhir kehidupannya.

\section{METODE}

\section{Populasi}

Populasi adalah seluruh penduduk atau individu yang paling sedikit mempunyai satu sifat yang sama. Populasi memiliki karakteristik yang dapat diperkirakan dan diklasifikasikan sesuai dengan keperluan penelitian (Hadi, 2000). Populasi dalam penelitian ini adalah lansia pensiunan suku Batak Toba.

\section{TeknikPengambilan Sampel}

\begin{tabular}{ccr} 
Penelitian & \multicolumn{2}{c}{ dilakukan untuk } \\
menggeneralisasikan & sampel dan menarik
\end{tabular} kesimpulan penelitian sampel sebagai sesuatu yang berlaku bagi populasi (Azwar, 2000). Sampel merupakan bagian dari populasi untuk dijadikan sebagai bahan penalaah dengan harapan contoh yang diambil dari populasi tersebut dapat mewakili (representative) terhadap populasinya (Supangat, 2007). Karakteristik sampel dalam penelitian ini adalah sebagai berikut:

1. Lanjut usia (lansia)

2. Pernah bekerja (pensiunan)

3. Suku Batak Toba

4. Beragama Kristen

Teknik pengambilan sampel yang digunakan dalam penelitian ini adalah Purposive Sampling, dimana pemilihan sekelompok subjek didasarkan atas ciri-ciri atau sifat-sifat tertentu yang dipandang mempunyai sangkut paut yang erat dengan ciri atau sifat populasi yang diketahui sebelumnya (Hadi, 2000).

\section{Pengumpulan Data}

Data dalam penelitian ini diambil dengan menggunakan alat ukur berupa 2 (dua) skala psikologis, yaitu Skala Psychological Well Being dan Skala Religiusitas yang disusun dalam bentuk Likert.

\section{Skala Psychological Well Being (PWB)}

Dimensi-dimensi Psychological Well Being menurut Ryff (dalam Ryff, 1989; Ryff \& Keyes, 1995) adalah: Dimensi penerimaan diri, Dimensi hubungan yang positif dengan orang lain, Dimensi otonomi, Dimensi penguasaan lingkungan, Dimensi tujuan hidup, Dimensi pertumbuhan pribadi

Setiap aspek di atas akan diuraikan kedalam sejumlah pernyataan favorable dan unfavorable, dimana subjek diberikan lima alternatif pilihan jawaban, yaitu Sangat Sesuai (SS), Sesuai (S), Tidak Sesuai (TS), dan Sangat Tidak Sesuai (STS). Untuk aitem favorable, pilihan SS mendapatkan skor empat, pilihan S mendapatkan nilai tiga, pilihan TS mendapatkan nilai dua, dan pilihan STS akan mendapatkan nilai satu. Sedangkan untuk aitem unfavorable, pilihan SS mendapat skor satu, pilihan $\mathrm{S}$ mendapat skor dua, pilihan TS mendapat skor tiga, dan pilihan STS mendapat skor empat.

\begin{tabular}{|c|c|c|c|c|}
\hline Dimensi PWB & Favorable & Unfavorable & - Jumlah & Persentase \\
\hline a. Penerimaan Diñ & $5,28,34,37$ & $12,25,30$ & 7 & $16.6 \%$ \\
\hline b. Hubungan positif & $7,24,35,41$ & $8,14,15$ & 7 & $16.6 \%$ \\
\hline c. Otonomi & $3,10,17,21$ & $9,18,20$ & 7 & $16.6 \%$ \\
\hline $\begin{array}{l}\text { d. Penguasaan } \\
\text { lingkungan }\end{array}$ & $2,16,32,42$ & $6,29,38$ & 7 & $16.6 \%$ \\
\hline e. Tujuan Hidup & $1,13,26$ & $27,31,33,40$ & 7 & $16.6 \%$ \\
\hline $\begin{array}{l}\text { f. Pertumbuhan } \\
\text { Pribadi }\end{array}$ & 19,36 & $\begin{array}{c}4,11,22,23, \\
39\end{array}$ & 7 & $16.6 \%$ \\
\hline Jumlah & 21 & 21 & 42 & $100 \%$ \\
\hline
\end{tabular}

\section{Skala Religiusitas}

Dimensi-dimensi religiusitas menurut Glock dan Stark (1962), antara lain: Dimensi keyakinan, Dimensi peribadatan,. Dimensi pengalaman, Dimensi konsekuensi, Dimensi pengetahuan agama. 
Setiap aspek di atas akan diuraikan kedalam sejumlah pernyataan favorable dan unfavorable, dimana subjek diberikan lima alternatif pilihan jawaban, yaitu Sangat Sesuai (SS), Sesuai (S), Tidak Sesuai (TS), dan Sangat Tidak Sesuai (STS). Untuk aitem favorable, pilihan SS mendapatkan skor empat, pilihan $S$ mendapatkan nilai tiga, pilihan TS mendapatkan nilai dua, dan pilihan STS akan mendapatkan nilai satu. Sedangkan untuk aitem unfavorable, pilihan SS mendapat skor satu, pilihan S mendapat skor dua, pilihan TS mendapat skor tiga, dan pilihan STS mendapat skor empat.

Tabel 2.

\begin{tabular}{|c|c|c|c|c|}
\hline \multicolumn{5}{|c|}{ Blue Print Skala Religiusitas Sebelum UjiCoba } \\
\hline Dimensi & \multicolumn{2}{|c|}{ Pernyataan } & \multirow{2}{*}{ Jumlah } & \multirow{2}{*}{ Persentase } \\
\hline Religiusitas & Favorable & Unfavorable & & \\
\hline a. Keyakinan & $1,15,23,30$ & 6,20 & 6 & $17.6 \%$ \\
\hline b. Peribadatan & $2,7,9,14$ & $24,27,32$ & 7 & $20.5 \%$ \\
\hline c. Pengalaman & $16,21,28,29,34$ & $3,10,12,22$ & 9 & $26.4 \%$ \\
\hline d. Konsekuensi & $5,13,18,19,33$ & $8,26,31$ & 8 & $23.5 \%$ \\
\hline e. Pengetahuan & 11,25 & 4,17 & 4 & $11.7 \%$ \\
\hline Jumlah & 20 & 14 & 34 & $100 \%$ \\
\hline
\end{tabular}

\section{Alat Ukur}

\section{Validitas \& Realibilitas}

Penelitian ini menggunakan face validity dan content validity. Face validity adalah tipe validitas yang paling rendah signifikansinya karena hanya didasarkan pada penilaian terhadap format penampilan (appearance) tes. Apabila penampilan tes telah meyakinkan dan memberikan kesan mampu mengungkap apa yang hendak diukur, maka dapat dikatakan bahwa face validity telah terpenuhi. Content validity berkaitan dengan item-item alat ukur sesuai dengan apa yang akan di ukur. Content validity diperoleh melalui pertimbangan dari profesional judgement yang memiliki kompetensi dalam bidang yang hendak diteliti (Azwar, 2000).

Uji reliabilitas alat ukur ini menggunakan pendekatan konsistensi internal dengan single trial administration yang mana prosedurnya hanya memerlukan satu kali pengenaan sebuah tes kepada sekolompok individu sebagai subjek (Azwar, 2010). Teknik yang digunakan untuk pengukuran reliabilitas alat ukur penelitian ini adalah teknik koefisien Alpha Cronbach, dimana batasan penerimaan reliabilitas dianggap memuaskan apabila koefisiennya mencapai nilai minimal 0.5 (Azwar, 2000).

\section{HASIL}

\section{Skala Psychological Well Being (PWB)}

Hasil uji coba skala Psychological Well Being (PWB) menunjukkan bahwa dari 42 aitem terdapat sebanyak 8 aitem dinyatakan gugur, yaitu aitem 4, 5, 17, 21, 26, 33, 37, 41. Koefisien korelasi aitem total yang memenuhi kriteria bergerak dari $r_{i t}=0.173$ sampai dengan $r_{i t}=$ 0.627 .

\begin{tabular}{|c|c|c|c|}
\hline \multirow{2}{*}{ Dimensi PWB } & \multicolumn{2}{|c|}{ Pernyataan } & \multirow{2}{*}{ Jumlah } \\
\hline & Favorable & Unfavorable & \\
\hline \multirow{6}{*}{$\begin{array}{l}\text { a. Penerimaan Diri } \\
\text { b. Hubungan positif dengan } \\
\text { orang lain } \\
\text { c. Otonomi } \\
\text { d. Penguasaan lingkungan } \\
\text { e. Tujuan Hidup } \\
\text { f. Pertumbuhan Pribadi }\end{array}$} & 28,34 & $12,25,30$ & 5 \\
\hline & $7,24,35$ & $8,14,15$ & 6 \\
\hline & $\begin{array}{l}3,10 \\
\text {. }\end{array}$ & $9,18,20$ & 5 \\
\hline & $2,16,32,42$ & $6,29,38$ & 7 \\
\hline & 1,13 & $27,31,40$ & 5 \\
\hline & 19,36 & $11,22,23,39$ & 6 \\
\hline Jumlah & 15 & 19 & 34 \\
\hline
\end{tabular}

diketahui bahwa setelah uji coba diperoleh 34 aitem yang memenuhi indeks daya beda aitem $\mathrm{r}_{\mathrm{i} i} \geq 0.173$ dengan reliabilitas sebesar 0.867 . Peneliti menggunakan 34 aitem yang lolos uji coba untuk alat ukur dalam penelitian. Selanjutnya dilakukan penomoran baru bagi aitem-aitem yang diikutsertakan dalam alat ukur pada saat penelitian.

\begin{tabular}{|c|c|c|c|}
\hline \multirow{2}{*}{ Dimensi PWB } & \multicolumn{2}{|c|}{ Pernyataan } & \multirow{2}{*}{ Jumlah } \\
\hline & Favorable & Unfavorable & \\
\hline g. Penerimaan Dini & $1,14,30$ & $4,17,29$ & 6 \\
\hline $\begin{array}{l}\text { h. Hubungan positif dengan } \\
\text { oranglain }\end{array}$ & $7,12,26$ & $2,20,32$ & 6 \\
\hline i. Otonomi & 16 & $11,23,33$ & 4 \\
\hline j. Penguasaanlingkungan & $3,8,19,34$ & $6,22,31$ & 7 \\
\hline k. Tujuan Hidup & 5,24 & $9,15,27$ & 5 \\
\hline I. Pertumbuhan Pribadi & 21,28 & $10,13,18,25$ & 6 \\
\hline Jumlah & 15 & 19 & 34 \\
\hline
\end{tabular}

\section{Skala Religiusitas}

Setelah diujicobakan pada subjek penelitian, dari 34 aitem yang terdapat pada skala religiusitas, terdapat sebanyak 6 (enam) aitem dinyatakan gugur, yaitu aitem 3, 4, 8, 12, 
20, 31. Koefisien korelasi aitem total yang memenuhi kriteria bergerak dari $r_{i t}=0.273$ sampai dengan $r_{i t}=0.718$.

\begin{tabular}{|c|c|c|c|}
\hline \multirow{2}{*}{ Dimensi Religiusitas } & \multicolumn{2}{|c|}{ Pernyataan } & \multirow{2}{*}{ Jumlah } \\
\hline & Favorable & Unfavorable & \\
\hline a. Keyakinan & $1,15,23,30$ & 6 & 5 \\
\hline b. Peribadatan & $2,7,9,14$ & $24,27,32$ & 7 \\
\hline c. Pengalaman & $16,21,28,29,34$ & 10,22 & 7 \\
\hline d. Konsekuensi & $5,13,18,19,33$ & 26 & 6 \\
\hline d. Pengetahuan & 11,25 & 17 & 3 \\
\hline Jumlah & 20 & 8 & 28 \\
\hline
\end{tabular}

diketahui bahwa setelah uji coba diperoleh 28 aitem yang memenuhi indeks daya beda aitem $\mathrm{r}_{\mathrm{i} t} \geq 0.173$ dengan reliabilitas sebesar 0.903 . Peneliti menggunakan 28 aitem yang lolos uji coba untuk alat ukur dalam penelitian. Selanjutnya dilakukan penomoran baru bagi aitem-aitem yang diikutsertakan dalam alat ukur pada saat penelitian.

\begin{tabular}{|c|c|c|c|}
\hline \multirow{3}{*}{ Dimanel Ralloluelitac } & $\begin{array}{r}\text { Tabal } 8 \\
\text { Kala Rallolucitac }\end{array}$ & dos bust Pa & \multirow{3}{*}{ Jumlah } \\
\hline & \multicolumn{2}{|c|}{ Parnyatesn } & \\
\hline & Fovorable & Untavorable & \\
\hline Q. Keycking & $1,12,14,28$ & 19 & 5 \\
\hline b. Feflodeden & $2,17,20,28$ & $5,7,10$ & 7 \\
\hline C. Fergelemen & $8,23,24,25,27$ & 15,22 & 7 \\
\hline d. Korsekuez & $4,8,11,18,21$ & 13 & 8 \\
\hline e. Fergetatuan & 9,16 & 3 & 3 \\
\hline Jumlah & 20 & 8 & 28 \\
\hline
\end{tabular}

Bab ini akan menguraikan analisa data dan pembahasan hasil penelitian sesuai dengan data yang diperoleh. Pembahasan dimulai dengan memberikan gambaran umum tentang subjek penelitian dilanjutkan dengan hasil penelitian, analisis dan interpretasi data penelitian serta pembahasan.

\section{Gambaran Umum Subjek Penelitian Usia Subjek Penelitian}

Tabel 7. Gambaran Subjek Penelitian Berdasarkan Usia

\begin{tabular}{ccc}
\hline $\begin{array}{c}\text { Usia } \\
\text { (Tahun) }\end{array}$ & Subjek & $\begin{array}{c}\text { Persentase } \\
(\%)\end{array}$ \\
\hline $60-64$ & 46 & 57.5 \\
$65-69$ & 15 & 18.75 \\
$70-74$ & 11 & 13.75 \\
$75-79$ & 8 & 10 \\
Total & $\mathbf{8 0}$ & $\mathbf{1 0 0}$ \\
\hline
\end{tabular}

Subjek dalam penelitian ini berdasarkan usia dengan penyebaran data seperti yang disajikan pada Tabel 7. di atas tergambar bahwa jumlah subjek subjek berusia 60-64 tahun sebanyak 46 orang jumlah subjek berusia 65-69 tahun sebanyak 15 orang, jumlah subjek berusia 70-74 sebanyak 11 orang, jumlah subjek berusia 75-79 tahun sebanyak 8 orang. Subjek yang paling dominan berusia 60-64 tahun berjumlah $57.5 \%$, usia 65-69 tahun berjumlah $18.75 \%$, usia 70-74 tahun berjumlah $13.75 \%$, usia 75-79 tahun berjumlah $10 \%$ dari keseluruhan jumlah subjek penelitian.

\begin{tabular}{|c|c|c|}
\hline $\begin{array}{c}\text { Jenis } \\
\text { Kelamin }\end{array}$ & Subjek & $\begin{array}{c}\text { Persentase } \\
(\%)\end{array}$ \\
\hline Pria & 53 & 66.25 \\
\hline Wanita & 27 & 33.75 \\
\hline Total & 80 & 100 \\
\hline
\end{tabular}

Subjek dalam penelitian ini berdasarkan jenis kelamin dengan penyebaran data seperti yang disajikan pada Tabel 8. di atas tergambar bahwa jumlah subjek pria sebanyak 53 orang dan subjek wanita 27 orang. Subjek pria $66.25 \%$ dari jumlah keseluruhan jumlah subjek penelitian, sedangkan subjek perempuan $33.75 \%$ dari keseluruhan jumlah subjek penelitian.

Lama Pensiun Subjek Penelitian

Tabel 9. Gambaran Subjek

Penelitian Berdasarkan Lama Pensiun

\begin{tabular}{ccc}
\hline $\begin{array}{c}\text { Lama } \\
\text { Pensiun }\end{array}$ & Subjek & $\begin{array}{c}\text { Persentase } \\
(\%)\end{array}$ \\
\hline 0 Bulan-6 & 35 & 43.75 \\
Tahun & & 27.5 \\
7-13 Tahun & 22 & 28.75 \\
14-20 Tahun & 23 & $\mathbf{1 0 0}$ \\
Total & $\mathbf{8 0}$ & \\
\hline
\end{tabular}

Subjek dalam penelitian ini berdasarkan lama pensiun dengan penyebaran data seperti yang disajikan pada Tabel 9. di atas tergambar bahwa jumlah subjek yang telah pensiun selama 0 bulan-6 tahun sebanyak 35 orang, jumlah subjek yang telah pensiun selama 7-13 tahun 
sebanyak 22 orang, jumlah subjek yang telah pensiun selama 14-20 tahun sebanyak 23 orang. Subjek yang telah pensiun dominan selama 0 bulan-6 tahun berjumlah $43.75 \%$, pensiun selama 7-13 tahun berjumlah $27.5 \%$, dan pensiun selama 14-20 tahun berjumlah $28.75 \%$ dari keseluruhan jumlah subjek penelitian.

\section{Uji Normalitas}

Uji normalitas digunakan untuk mengetahui apakah distribusi data penelitian masing-masing variabel menyebar secara normal. Uji normalitas pada penelitian ini menggunakan One Sample Kolmogorov-Simirnov Test dengan bantuan aplikasi komputer SPSS version 20.0 for Windows. Data dapat dikatakan terdistribusi secara normal jika nilai $\mathrm{p}>0.05$.

Tabel 10. Hasil Uji Normalitas

\begin{tabular}{lcc}
\hline Variabel & $\begin{array}{c}\text { Kolmogorov- } \\
\text { Smirnov Z }\end{array}$ & Sig. \\
\hline $\begin{array}{l}\text { Psychologi } \\
\text { cal Well }\end{array}$ & 1.170 & 0.129 \\
$\begin{array}{l}\text { Being } \\
\text { Religiusitas }\end{array}$ & 0.966 & 0.308 \\
\hline
\end{tabular}

Dari Tabel 10. di atas dapat diketahui bahwa pada variabel Psychological Well Being diperoleh nilai $\mathrm{Z}$ sebesar 1.170 dengan nilai signifikansi sebesar 0.129 dan pada variabel religiusitas diperoleh nilai $\mathrm{Z}$ sebesar 0.966 dengan nilai signifikansi sebesar 0.308. Nilai Z dan nilai signifikansi untuk kedua variabel lebih besar dari 0.05, dengan demikian dapat disimpulkan bahwa data penelitian pada variabel Psychological Well Being dan religiusitas terdistribusi secara normal.

\section{Uji Linearitas}

Uji linearitas berguna untuk mengetahui apakah variabel-variabel dalam penelitian memiliki hubungan yang linear atau tidak. Uji ini merupakan prasyarat dalam analisis korelasi atau regresi linear.

Uji linearitas pada penelitian ini menggunakan Uji $\mathrm{F}$ dengan bantuan aplikasi komputer SPSS version 20.0 for Windows, dimana variabel dikatakan memiliki hubungan yang linear jika nilai Sig. Linearity lebih kecil dari 0.05 dan nilai Sig. Deviation from Linearity lebih besar dari 0.05.

\begin{tabular}{|c|c|c|c|c|}
\hline \multicolumn{5}{|c|}{ Tabel 11. Hasil Uji Linearitas } \\
\hline & & & $F$ & Sig. \\
\hline \multirow[t]{6}{*}{ PWB*Religi } & Between Groups & (Combined) & 2.462 & .002 \\
\hline & & Linearity & 27.075 & .000 \\
\hline & & Deviationfrom & 1.693 & .050 \\
\hline & & Linearity & & \\
\hline & Within Groups & & & \\
\hline & Total & & & \\
\hline
\end{tabular}

Dari Tabel 11. di atas dapat diketahui bahwa nilai Sig. Linearity sebesar 0.000 (lebih kecil dari 0.05), dan nilai Sig. Deviation sebesar 0.050 (lebih besar dari 0.05). Hal ini menunjukkan bahwa antara variabel Psychological Well Being (PWB) dan religiusitas memiliki hubungan linear.

Berikut ini akan dijelaskan mengenai hasil pengolahan data penelitian pengaruh religiusitas terhadap Psychological Well Being (PWB) pada pensiunan Suku Batak Toba. Data penelitian ini diolah menggunakan teknik analisis regresi sederhana dengan bantuan aplikasi komputer SPSS version 20.0 for Windows.

Tabel 12. Koefisien Determinan

\begin{tabular}{lcccc}
\hline Model & \multicolumn{4}{c}{ Adju } \\
& $\mathbf{R}$ & $\begin{array}{c}\mathbf{R} \\
\text { sted } \\
\mathbf{R}\end{array}$ & $\begin{array}{c}\text { Std.Error of the } \\
\text { Estimate }\end{array}$ \\
& & & $\begin{array}{c}\text { Squa } \\
\text { re }\end{array}$ \\
\hline 1 & .461 & .213 & .203 & 6.598 \\
\hline
\end{tabular}

Berdasarkan Tabel 12. di atas, hasil data yang diolah yakni nilai $\mathrm{R}$ adalah 0.461 , yang menjelaskan bahwa antara kedua variabel terdapat korelasi yang kuat dan positif, dimana setiap kenaikan variabel religiusitas menyebabkan kenaikan variabel Psychological Well Being. Nilai $\mathrm{R}^{2}$ sebesar 0.213,yang artinya $21.3 \%$ variabel religiusitas menjelaskan variabel Psychological Well Being sedangkan 78.7\% sisanya dijelaskan oleh faktor-faktor lain. 
Tabel 13. Anova

\begin{tabular}{|c|c|c|c|c|c|c|}
\hline Model & & $\begin{array}{l}\text { Sum of } \\
\text { Squares }\end{array}$ & df & $\begin{array}{l}\text { Mean } \\
\text { Square }\end{array}$ & $\mathrm{F}$ & Sig. \\
\hline \multirow{3}{*}{1} & Regression & 917.760 & 1 & 917.760 & 21.085 & .000 \\
\hline & Residual & 3395.128 & 78 & 43.527 & & \\
\hline & Total & 4312.887 & 79 & & & \\
\hline
\end{tabular}

Berdasarkan hasil analisis pada Tabel 13. diatas, nilai signifikannya adalah 0.000 (lebih kecil dari 0.05) dan nilai $F$ hitung sebesar 21.085 (lebih besar dari F Tabel) maka Ho ditolak. Hal ini menunjukkan bahwa ada pengaruh religiusitas terhadap Psychological Well Being pada pensiunan Suku Batak Toba.

Tabel 14. Parameterparameter Persamaan Garis Regresi

\begin{tabular}{lrrr}
\hline \multicolumn{1}{c}{ Model } & \multicolumn{1}{c}{ B } & \multicolumn{1}{c}{ T } & Sig. \\
\hline (Constant) & 62.881 & & \\
Religiusita & & 4. & \\
s & .348 & 59 & .000 \\
& & 2 & \\
\hline
\end{tabular}

Persamaan garis regresi pada penelitian ini adalah $\mathrm{Y}=\mathrm{a}+\mathrm{bX}$, dimana Psychological Well Being dilambangkan dengan (Y) dan religiusitas (X). Berdasarkan hasil analisa data pada Tabel 14. diatas, persamaan garis regresinya adalah $\mathrm{Y}=62.881+0.348 \mathrm{X}$. Persamaan garis regresi ini menunjukkan jika tidak ada religiusitas maka skor Psychological Well Being pada pensiunan Suku Batak Toba adalah 62.881. Koefisien regresi sebesar 0.348 pada religiusitas menggambarkan bahwa setiap penambahan satu satuan variabel religiusitas akan meningkatkan Psychological Well Being sebesar 0.348.

\section{DISKUSI}

Penelitian ini dilakukan terhadap 80 orang lansia yang pernah bekerja (pensiunan), Suku Batak Toba dan beragama Kristen. Berdasarkan data-data yang telah didapatkan, diuji, dan dianalisis, peneliti memperoleh hasil yaitu ada pengaruh religiusitas terhadap Psychological Well Being pada pensiunan Suku Batak Toba.
Pengaruh tersebut dapat dilihat dari nilai signifikansi sebesar 0.000 (lebih kecil dari 0.05) sehingga Ho ditolak dan Ha diterima, dimana hal tersebut berarti adanya pengaruh religiusitas terhadap Psychological Well Being pada pensiunan Suku Batak Toba.

Hasil penelitian ini sejalan dengan teori dari Ellison (dalam Trankle, 2009) yang menjelaskan bahwa pada individu dengan religiusitas yang tinggi, berkontribusi terhadap tingkat Psychological Well Being yang lebih tinggi dan semakin sedikit dampak negatif yang dirasakan dari peristiwa traumatik dalam hidup.

Dari hasil analisis, ditemukan bahwa besarnya pengaruh religiusitas terhadap Psychological Well Being pada pensiunan Suku Batak Toba adalah 21.3\%, sedangkan $78.7 \%$ lainnya dijelaskan oleh faktor-faktor lain yang tidak diteliti dalam penelitian ini. Walaupun pengaruh religiusitas terhadap Psychological Well Being pada pensiunan Suku Batak Toba lemah, namun religiusitas merupakan variabel yang signifikan untuk melihat Psychological Well Being pada pensiunan Suku Batak Toba. Hal ini juga ditunjukkan pada hasil penelitian Maulina (2011), bahwa Psychological Well Being pada lansia dapat dijelaskan dengan tinggi rendahnya religiusitas. Selain itu, penelitian oleh Koenig, Smiley, dan Gonzales (dalam Santrock, 2008) menunjukkan hasil bahwa kegiatan keagamaan seperti berdoa, membaca kitab suci, dan perasaan religius berkaitan dengan Psychological Well Being terutama bagi para lansia.

Jika dilihat berdasarkan dimensi-dimensi Psychological Well Being, dimensi hubungan positif dengan orang lain, penguasaan lingkungan, tujuan hidup, dan pertumbuhan pribadi menunjukkan adanya pengaruh religiusitas terhadap Psychological Well Being pada pensiunan Suku Batak Toba, sedangkan dimensi penerimaan diri dan otonomi menunjukkan tidak adanya pengaruh religiusitas terhadap Psychological Well Being pada pensiunan Suku Batak Toba. Penerimaan diri dan otonomi terkait dengan dengan status sosial ekonomi seseorang (Ryff, 1995). Bagi masyarakat Suku Batak Toba, kekayaan, seperti: uang, benda-benda berharga, kesehatan, keturunan yang banyak, merupakan salah satu 
unsur cita-cita dan tujuan hidup yang dinamakan hamoraon. Bentuk kekayaan tersebut dapat dipergunakan untuk memperoleh status yang diidamkan dalam masyarakat, yang terkadang dilakukan melalui cara yang paling terhormat hingga paling kasar, padahal nilai religiusitas Kristiani mengharapkan seseorang menjadi pribadi yang aman, tertib, dan damai (Simanjuntak, 2009).

\section{Kesimpulan}

Berdasarkan hasil analisa dan pembahasan, dapat ditarik kesimpulan mengenai hasil utama penelitian, yaitu:

1. Ada pengaruh religiusitas terhadap Psychological Well Being pada pensiunan Suku Batak Toba $(\mathrm{R}=0.461 ; \mathrm{p}=0.000)$, artinya semakin tinggi religiusitas pensiunan Suku Batak Toba, maka berkontribusi terhadap kenaikan Psychological Well Being.

2. Sumbangan efektif yang diberikan variabel religiusitas terhadap variabel Psychological Well Being pada pensiunan Suku Batak Toba adalah sebesar 21.3\% $\left(\mathrm{R}^{2}=0.213\right)$, yang berarti bahwa pada penelitian ini religiusitas mempengaruhi Psychological Well Being sebesar 21.3\% dan sisanya dipengaruhi oleh faktor-faktor lain.

\section{Saran}

Berdasarkan penelitian yang telah dilakukan dan kesimpulan yang dikemukakan, maka peneliti mengemukakan beberapa saran. Saran-saran yang dikemukakan diharapkan dapat bermanfaat bagi perkembangan studi ilmiah.

1. Saran Metodologis

a. Untuk peneliti yang tertarik meneliti variabel Psychological Well Being, agar lebih melihat lagi variabel-variabel lainnya yang dapat mempengaruhi Psychological Well Being selain dari faktor religiusitas, seperti faktor demografis, dukungan sosial, dan evaluasi pengalaman hidup, sehingga memperkaya hasil penelitian tentang Psychological Well Being pada pensiunan.

b. Bagi peneliti yang tertarik meneliti variabel religiusitas, agar lebih memperhatikan penyebaran alat ukur, yang tidak terbatas (mayoritas) pada lansia yang memang aktif dan memiliki pelayanan dalam kegiatan keagaaman.

c. Penelitian selanjutnya mempertimbangkan status sosial ekonomi para pensiunan yang beragam, yang menjadi salah satu hal yang mempengaruhi Psychological Well Being.

d. Alat ukur penelitian memperhatikan penyesuaian aitem dari setiap dimensi religiusitas, misalnya penurunan aitem dimensi peribadatan yang tidak terbatas dengan datang ke tempat ibadah secara langsung.

2. Saran Praktis

Peneliti memberikan saran praktis bagi individu yang memiliki keluarga yang tergolong lansia, yang tidak lagi bekerja (pensiunan) :

a. Bagi lansia pensiunan, agar tetap menjaga hubungan baik dengan keluarga, teman, dan masyarakat di sekitarnya karena dukungan dari keluarga dan lingkungan sangat mempengaruhi Psychological Well Being dan perubahan-perubahan tidak terduga lainnya pada masa pensiun.

b. Bagi lansia pensiunan, agar lebih menyediakan waktu beribadah dan mendekatkan diri kepada Tuhan untuk mempertahankan maupun meningkatkan nilai religiusitasnya dalam hidup beragama dan menghadapi situasi atau masalah dalam kehidupan di masa pensiun.

\section{REFERENSI}

Andrews, F.M., Robinson, J. P., 1991. Measures of Subjective Well-Being, in Robinson, J. P. , Shaver, P. R., Wrightsman, L. S. (Eds.), Measures of Personality and Social Psychological Attitudes, San Diego, CA: Academic Press, pp. 61-114.

Azwar, S. (2000). Metodologi Penelitian. Yogyakarta: Pustaka Pelajar.

Azwar, S. (2010). Penyusunan Skala Psikologi. Yogyakarta: Pustaka Pelajar.

Badan Pusat Statistik Kota Medan, 2010. Medan Dalam Angka 2010, Badan Pusat Statistik Kota Medan.

Bastaman, H.D. (2007). Logoterapi: Psikologi untuk Menemukan Makna Hidup dan 
Meraih Hidup Bermakna. Jakarta: PT. Raja Grafindo Persada.

Bock, W.SJ. (2010). Usia Lanjut yang Berahmat dan Berdaya Pikat. Jakarta: Obor.

Brotoraharjo, S. Dr, MM, APU. (2007). Muda Berkarya, Tua Bahagia. Yogyakarta: Andi.

Calhoun, James F. (1995). Psychology of Adjustment and Human Relationship (3rd Edition). New York: McGraw-Hill.

Cavanaugh, J.C. (2006). Adult Development and Aging. USA: Wadsworth Thomson Learning.

Cornwall et al. (1986). The Dimension of Religiosity: A Conceptual Model With an Empirical Test. Review of Religious Research 27 (3), 226-243.

Corsini, R.J. (1987). The concise Encyclopedia of Psychology. Canada: John Willey \& Sons.

Field, A. (2009). Discovering Statistics Using SPSS (3rd Edition). London: SAGE Publications Ltd.

Francis, J. (2001). The Development of a Psychological Theory. Journal of Personality and Social Psychology, 65, 1259-1269.

Guilford, J.P. (1978). Fundamental Statistics in Psychology and Education (6th edition). New York: McGraw-Hill.

Glock, C.Y. (1962). On the Study of Religious Commitment. Journal of Religious Education, 57, 98-110.

Hadi, S. (2000). Metodologi Research. Yogyakarta: Penerbit Andi Offset.

Hoyer, W.J., \& Roodin, P.A. (2009). Adult Development and Aging. New York: McGraw-Hill.

Hurlock, E.B. (2002). Developmental Psychology : A life Time Approach (5th edition). New York: McGraw-Hill.
Hutapea, B. (2011). Emotional Inteliigence dan Psychological Well Being pada Manusia Lanjut Usia Anggota Organisasi berbasis Keagamaan di Jakarta. Insan. Vol. 13, No. 02, hal 69-70.

Jacinta, F.R. (2001). Pensiun dan Pengaruhnya. http://www.epsikologi.com/usia/pensiun.html

Koenjaraningrat. (2002). Manusia dan Kebudayaan di Indonesia. Jakarta: Djambatan.

Kwon, O. (2003). Buddhist and protestant korean immigrants: Religious beliefs and socioeconomic aspect of life. New York: LFB Scholarly Publishing LLC.

Maulina, S. (2011). Hubungan Religiusitas dengan Psychological Well Being pada Lansia. Jurnal Psikologi Univ. Gunadarma, hal 16-17.

Papalia, D.E. (2001). Human development 5th ed. New York: McGraw-Hill.

Papalia, D. E., Olds, S. W., Feldman, R. D. (2008). Human development (11th edition). New York: McGraw-Hill.

Ratri, D. (2010). Family's Social Support and Psychological Well Being of the Elderly in Tembalang. Anima. Vol. 26, No. 1, 61-68.

Rosyid, H.F. (2003). PHK: Masihkah mencemaskan.

http://inparametric.com/bhinablog/downl oad/phk_masihkah_mencemaskan.pdf

Ryff, D.C. (1989). Happines is everything, or is it? Explorations on the meaning of psychological well-being. Journal of personality and social psychology, 57 (6), 1069-1081.

Ryff, C.D., \& Essex, M.J. (1992). The interpretation of life experience and wellbeing: The sample case of relocation. Psychology and Aging, 7, 507-517.

Ryff, C.D. (1995). Psychological Well-Being in Adult Life. Current Directions in Psychological Science, Vol 4: 99-104.

Santrock, J.W. (1998). Life-span development $3 r d$ Ed. New York: McGraw-Hill 
Santrock, J.W. (2008). Life-span development 12th Ed. New York: McGraw-Hill.

Sarafino, E.P. 1994. Health Psychology : Biopsychosocial Interactions 7 th Ed. New York: John Wiley \& Sons, Inc.

Simanjuntak, B.A. (2009). Konflik Status dan Kekuasaan Orang Batak Toba (Bagian Sejarah Batak). Jakarta: Yayasan Obor Indonesia.

Siyelman, C.K. \& Rider, E.A. (2003). Life-Span Human Development 4th Ed. United States of America: Wadswort Thomson Learning, Inc.

Tampubolon, J.C. (1964). Pendekatan Kebudayaan dalam Pembangunan. Yogyakarta: Kelompok Penelitian Sosial dan Politik.

Thouless, R.H. (2000). Pengantar Psikologi Aga ma. Penerjemah:Machun Husein. Jakarta : PT. Raja Grafindo Persada.

Tulus, A. (1996). Managemen Sumber Daya Manusia. Jakarta : Kerjasama APTIK \& PT. Gramedia Pustaka Utama. 